\title{
A way to reduce friction between ring and traveller of a ring spinning frame
}

\author{
H. A. Begum*a and M. M. Helali ${ }^{b}$ \\ a Department of Yarn Manufacturing, Bangladesh University of Textiles, Tejgaon, Dhaka-1208, Bangladesh \\ ${ }^{b}$ Department of Mechanical Engineering, Bangladesh University of Engineering and Technology, \\ Dhaka-1000,Bangladesh
}

\begin{abstract}
The paper presents a method, which applied to the ring of the ring spinning machine will improve its productivity. Through the system vibration is applied on the ring-traveller, which has effects on the centrifugal force of the traveller and helps the traveller to rotate around ring with intermittent contact. The effect of vibration on yarn tension as well as friction between the ring and the traveler and the corresponding raise in temperature of the ring during spinning are measured.

An external facility is designed and incorporated in a miniature ring spinning frame to generate and apply vibration to the ring. The miniature ring spinning frame has the facility to vary twist and count of yarn and is modified to vary the spindle speed. Study shows that the ringtraveller friction is affected by the application of vibration. Results obtained with and without the applications of vibration are compared. It is found that yarn tension and friction between the ring and the traveller reduce significantly depending on the type of vibration.

Therefore it can be concluded that application of vibration may be a way to reduce friction between the ring and the traveler and thus the mechanical process of twisting and winding can be done at higher speed for higher productivity which is a limiting factor of ring spinning system.
\end{abstract}

Keywords: Friction; Vibration; Ring; Traveller and Yarn tension

\section{Introduction}

Ring spinning is an important spinning system for making spun yarn from different short to medium staple length fibers in the textile industry. As per quality concern of yarn, this system is best, flexible and most widely used yarn manufacturing system, but low productivity is one of the remarkable limitations of this system due to the limited speed (max 40 meter/sec) of traveller. It is well known that the traveller speed is limited due to friction between the ring and the traveller, which increases the temperature of traveller and finally it breaks and flies out. (Barr 1965, Klein 1995, Grossberg 1999 and Lord 2003).

The co-efficient of friction between the contacting surfaces depends on type of material, surface characteristics and conditions, relative motion and vibration etc. (Archard 1980, Arnov 1984a and Bushan 1999, 1991). Vibration may increase or decrease friction between contacting bodies, which depends on surface characteristics, area of contact, sliding velocity, contact pressure and temperature etc. (Bushan 1991, Godfray 1999, Skare 1967 and Chowdhury 1992). Researcher also claimed that frictional force may increases or decreases depending also on the vibration parameters(velocity, acceleration, frequency and amplitude). It can be noted that no established correlation between coefficient of friction and vibration related parameters exists. Considering the above findings and lack of correlation, the present research was aimed to study the effect of vibration on friction between the ring and the traveller.

Many researches have been carried out to reduce the frictional force between the ring and the traveller by modifying surfaces and surface contact area of the ring and the traveller. So far as knowledge goes no reported work was found which applied vibration to reduce frictional force between the ring and the traveller of the ring spinning frame. (Barr 1965, Klein 1995, Grossberg 1999 and Lord 2003).

\section{Materials and methods}

An experimental set-up is designed and fabricated to generate vibration at the ring of the ring spinning machine by the 
positive transverse displacement motion, which is given through transverse direction. The construction and working principle of the set-up with Figure 1 is given below (Begum 2012).

\section{Construction and working principle}

A spindle with corrugated surface (fluted spindle) is designed and fabricated in such a way, that it can be placed at the normal position of the spindle with existing facilities. To rotate this fluted spindle, power is transferred through flexible belt from a variable frequency drive, which is used to vary the speed of the motor as required.

A screw is placed vertically at the ring holder. A vibration transferring arm is connected from ring holder to fluted spindle, which is pivoted at the middle position on a platform. Two springs with small disk are set tangentially on the front part of the platform, which forces the arm to stay on the contact of the fluted spindle. The arrangement with platform placed on the ring rail and fitted tightly by four sets of screw.

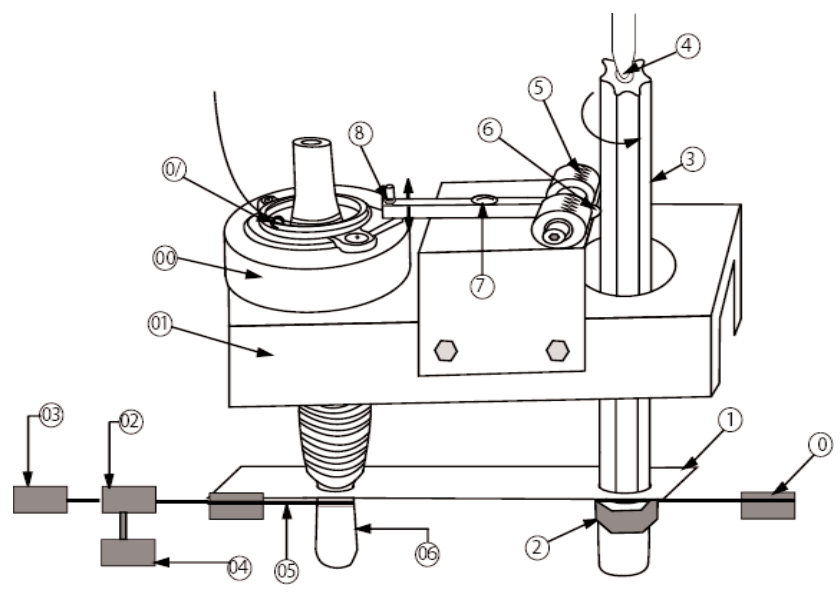

$1=$ variable frequency drive, $2=$ Bobbin rail, $3=$ Nut, $4=$ Fluted spindle, $5=$ Fluted spindle supporter, $6=$ Helical Spring $7=$ To and fro motion transferring arm, $8=$ Pivot, $9=$ Long screw with nut, $10=$ Traveller, $11=$ Ring base, $12=$ Ring rail, $13=$ Motor pulley, $14=$ Variable frequency drive, $15=$ Motor, $16=$ Belt.

\section{Fig. 1. Schematic diagram of the experimental set-up}

During rotation of the fluted spindle, front end of vibration transferring arm creates to and fro transverse motion. This to and fro motion generates vibration to the ring holder as well as the ring.

To do the experiment, the following parameters (Table-I) are selected and during experiment the following measurements (Table II) are recorded:
Table I. Experimental condition

\begin{tabular}{lc}
\hline Name of the Parameter & $\begin{array}{c}\text { Selected material and value } \\
\text { for experiment }\end{array}$ \\
\hline Type of fiber & Polyester(PET) \\
& multifilament $(3.5 \mathrm{D} \times 72)$ \\
Yarn count $(\mathrm{Ne})$ & 16 \\
Twist per inch & 18 \\
Ring diameter $(\mathrm{mm})$ & 45 \\
Traveller weight & $0.045-0.049$ gm (Breaker) \\
\hline
\end{tabular}

Table II. Measuring instrument and measurement

\begin{tabular}{lc}
\hline $\begin{array}{l}\text { Name of the Measuring } \\
\text { Instrument }\end{array}$ & $\begin{array}{c}\text { Parameters measured/ } \\
\text { Calculated }\end{array}$ \\
\hline Vibration Measuring & Displacement and \\
Meter METRIX Instrument Co & Velocity of vibration \\
Yarn Tension Measuring & Yarn Tension (Average, \\
Meter SCHMIDT, Germany & $\begin{array}{c}\text { Minimum, Maximum } \\
\text { and Peak value) }\end{array}$ \\
Digital Tachometer & Spindle speed \\
\hline
\end{tabular}

To asses the effect of vibration on the yarn tension at different spindle speeds, the vibration is applied at the ring, which has frequency and amplitude $475 \mathrm{~Hz}$ and $0.5 \mathrm{~mm}$ respectively. To compare the effect of vibration on yarn tension during spinning, five different spindle speeds $(3200,5200,7500$, 9500 and 11500 r.p.m) and polyester(PET) multifilament are selected on the basis of experimental facilities (accurate measurement of yarn tension and easy detection of melting spot). Multifilament is supplied through front drafting roller without draft. It is also mentioned here that yarn tension is measured in front of lappet.

During spinning, ring rail always traverses up and down along a certain length of bobbin and consequently yarn is wound on that place of bobbin. At the time of spinning, different types of forces act on the yarn e.g friction with lappet and traveller, resistance of air drag and winding tension etc. These forces are changed as different types of variable speed acts on yarn. Such as (i)one is traveling lengthwise(variable) from nip point of front drafting roller to winding point of bobbin through lappet and traveller (ii)another one is rotating with traveller. As a result variable tension is developed at yarn, due to variable forces, which are measured by the tension meter with the name of average, minimum, maxi- 
mum and peak-value. Yarn tension meter can capture 60 readings per second and each data was measured and recorded during one minute. Similarly data are taken five times at particular spindle speed and presented in mean result.

\section{Results and Discussion}

\section{Effect of vibration on yarn tension}

\section{Average value of yarn tension}

Fig. 2(a) shows the average value of yarn tension at five different spindle speeds (different velocity of traveller) with and without application of vibration and it is seen that, at every step of spindle speeds $(3200,5200,7500,9500$ and 11500 r.p.m) the average value of yarn tension decreases due to effects of vibration on the ring.

Fig. 2(b) shows the percent reduction of average value of yarn tension for five different spindle speeds and this reduction varies from $15 \%$ to $20 \%$. It is found that the average values of yarn tension increases with the increasing spindle speed. No specific co-relation between percentage reduction of the average value of yarn tension with the increase of spindle speed is found.

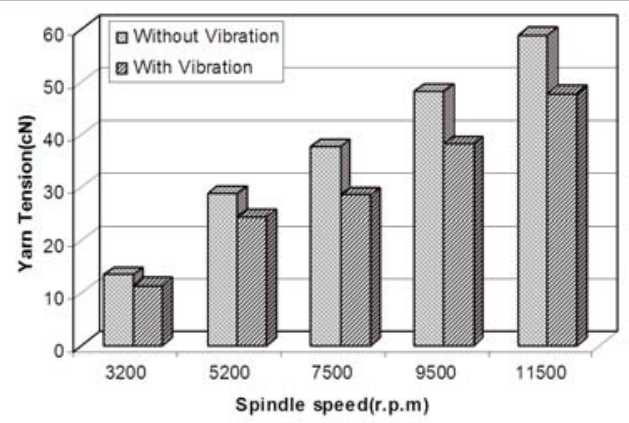

Fig. 2(a). Average value of yarn tension at different spindle speeds with and without effect of vibration.(Transverse direction)

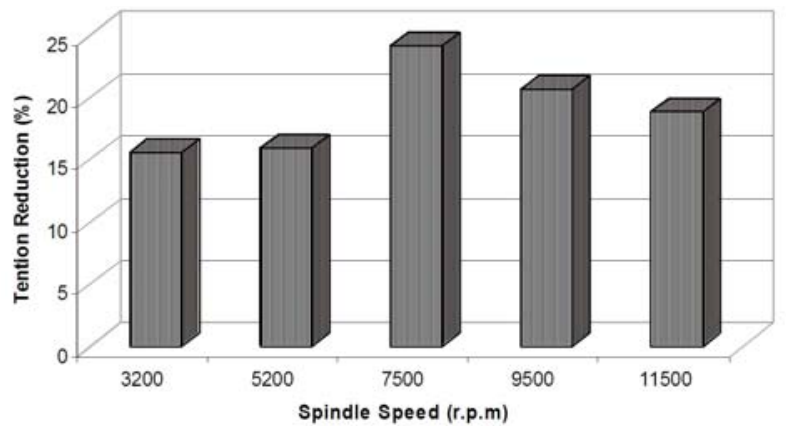

Fig. 2(b). Percentage reduction of average value of yarn tension at different spindle speeds with effect of vibration. (Transverse direction)

\section{Minimum value of yarn tension}

Fig. 3(a) represents the comparison of minimum value of yarn tension at five different spindle speeds. These values of yarn tension decreases at each spindle speed due to the vibration of the ring. The amount of percent reduction of minimum value of yarn tension is presented in Fig. 3(b) and from this figure it is also clear that percent reduction of minimum value of yarn tension varies from $8.3 \%-25.5 \%$. In this case no co-relation is also observed.

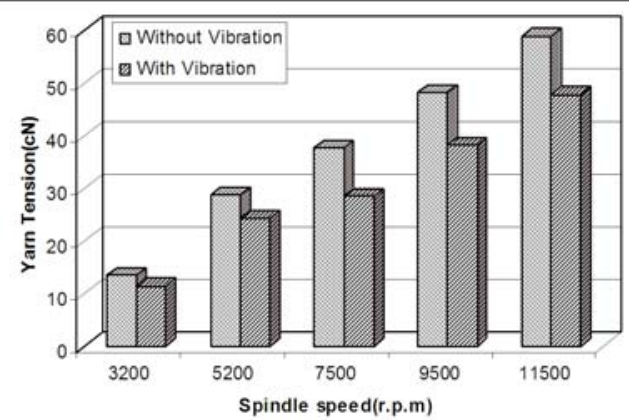

Fig. 3(a). Minimum value of yarn tension at different spindle speeds with and without effect of vibration

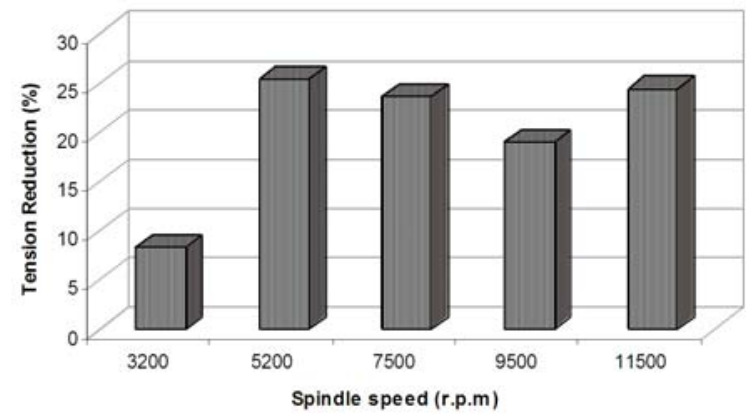

Fig. 3(b). Percentage reduction of minimum value of yarn tension at different spindle speeds with effect of vibration

It is observed that maximum and peak value of yarn tension show similar trend as the average and minimum tension. Fig. 4(a), 4(b), 5(a) and 5(b) shows the comparison of tension and percent reduction of tension of maximum and peak value. Peak values are $2-10 \%$ higher than maximum values.

From Fig. 2(b), 3(b), 4(b) and 5(b), it is seen that decrease rate of average, maximum and peak value of yarn tension varies from $12-20 \%$ but percent reduction of minimum tension reduces $8-25$. It may be mentioned that different parameters of the generated vibration might not be perfectly same, which might have effect on the results. 


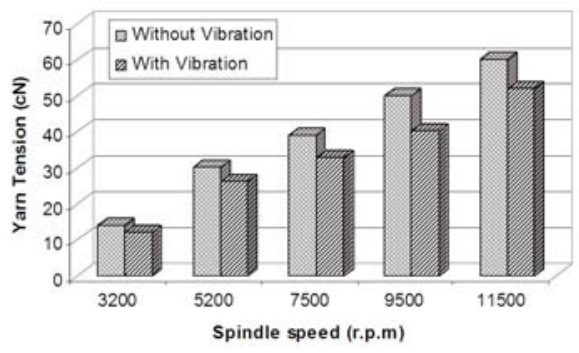

Fig. 4(a). Maximum value of yarn tension at different spindle speeds with and without effect of vibration

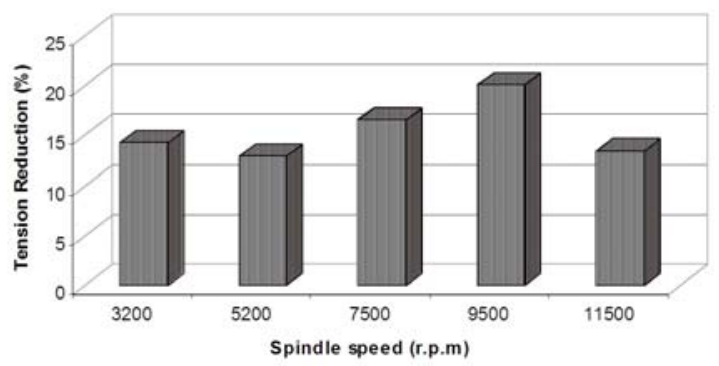

Fig. 4(b). Percentage reduction of maximum value of yarn tension at different spindle speeds with effect of vibration

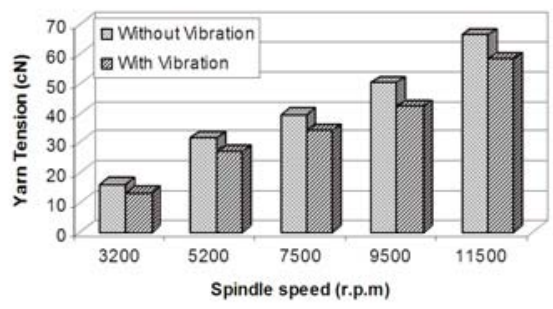

Fig. 5(a). Peak value of yarn tension at different spindle speeds with and without effect of vibration

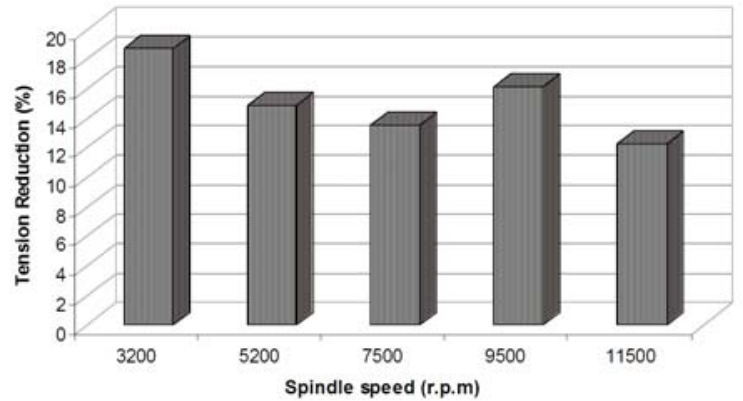

Fig. 5(b). Percentage reduction of Peak value of yarn tension at different spindle speeds with effect of vibration

\section{Effect of Vibration on Ring Temperature}

During running of traveller on ring rail, temperature generates at the contact surface of the ring and the traveller due to friction. Due to high rotational speed of traveller, its temperature measurement could not be done due to the lack of the facilities. K-type thermocouple is shown in Figure 6, is used to measure the ring temperature as close as possible the contacting surface of the traveller. Temperature of the ring is measured continuously for 16 minutes from start. It is tried to run the experiment at the same ambient atmosphere.

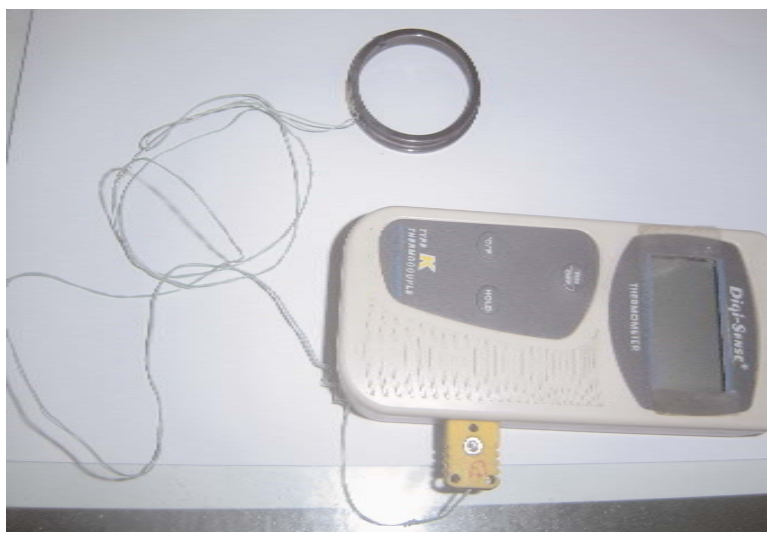

Fig. 6. Measurement of ring temperature by $K$ type thermocouple system

Figure 7 shows the percent reduction of ring temperature at five different spindle speeds with application of vibration during spinning. This reduction of ring temperature maintains approximate similar tendency as tension reduction value.

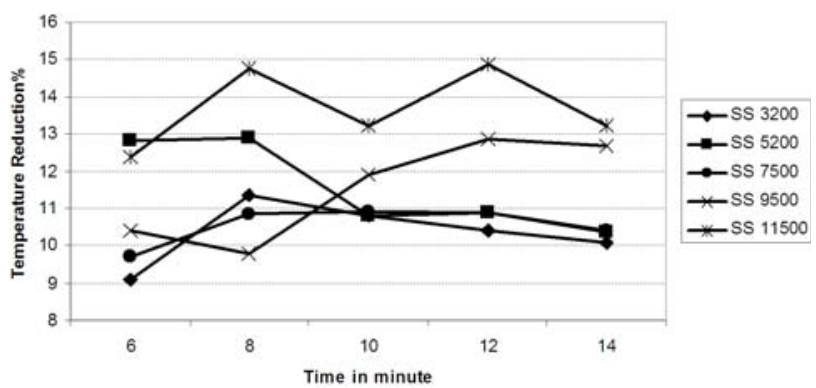

Fig. 7. Percentage reduction of ring temperature at different spindle speeds with application of vibration

Percentage reduction of ring temperature is varied also 9$15 \%$ due to spindle speed of $3200-11500 \mathrm{rpm}$. This reduction of the ring temperature indicates the reduction of frictional force for application of vibration at the ring. 
Vibration is one kind of oscillating motion and this oscillating motion of the ring induces the traveller to maintain intermittent contact with the ring. This reduction of contact time and area of contact have influence on the reduction of temperature of the contacting surface of ring and traveller and hence the rise of temperature is decreased. The same reason may be valid to the reduction of yarn tension.

Now it can be summarized that application and generation of vibration at the ring and the traveller is a new way, which assist the traveller to run with intermittent contact on the ring surface. This process reduces yarn tension, as same as generation of temperature of contacting surfaces (the ring and the traveller) and as well as its friction co-efficient (Barr 1965, Grossberg 1999 and Lord 2003). To maintain the present running condition i.e the same friction, about $10 \%$ spindle speed can be increased with the application of vibration. This will increase the production of a spinning machine.

\section{Effect of Vibration on Cotton Spun Yarn Properties}

To understand the effects of vibration on cotton spun yarn properties, two fineness of cotton yarns are manufactured from same cotton fiber (Table III). Production parameters are given in Table IV.

\section{Table III. Properties of cotton fiber}

\begin{tabular}{lc}
\hline Fiber Properties & Value \\
\hline Length & $30 \mathrm{~mm}$ \\
Strength & $26 \mathrm{gm} / \mathrm{tex}$ \\
Fineness & 3.6 micronaire \\
Maturity & $0.9 \%$ \\
Neps & 140 neps/gm \\
\hline
\end{tabular}

The spindle speed of the miniature spinning machine is 10000 r.p.m selected and processing atmosphere of all yarns is tried to keep almost same. At the beginning of every sample manufacturing a new traveller is replaced by the old one. It is also noted that all the sample yarns are produced from the same fiber. Strength, elongation and evenness of yarns are measured by Titan universal strength tester and Uster tester4 respectively. ASTM D2256 $(250 \mathrm{~cm}, 20 \mathrm{sec})$ method was selected to do the breaking strength of the sample. The properties of both yarns, which are produced by miniature ring spinning frame with and without vibration, are presented in Table V.

The properties of both the yarns (10 and $20 \mathrm{Ne})$ are slightly affected by vibration. The breaking strength of both the yarns increase 6- $8 \%$ and elongation properties increase more than $30 \%$ (for $20 \mathrm{Ne}$ ). Mainly the structure of yarn formation is being begun at the spinning triangle and the newly formed yarn is going forward through the lappet and the traveller at the direction of winding point. Yarn is running and moving with high tension. The oscillating motion of the traveller is very little (0.1-0.5millimeter), which helps to reduce the contact pressure of the yarn and the traveller a little and at the same time helps to reduce the surface scraping of the yarn. The yarn compactness is not interrupted by the effect of vibration. This may be a reason to increase strength by a few percentages. Normally the loose fibers of yarn are agglomerated at the inner side of traveller and sometimes come out with the yarn. But due to the effect of vibration, there is no chance to stay the scrapping fiber between the

\section{Table IV. Parameters for the production of cotton yarn}

\begin{tabular}{lcc}
\hline Parameter & Yarn - I & Yarn - II \\
\hline Yarn count (Ne) & 10 & 20 \\
Twist per inch & 15 & 18 \\
Traveller No. & $1 / 0$ & $2 / 0$ \\
Spindle speed(r.p.m) & 10000 & 10000 \\
Frequency of vibration $(\mathrm{Hz})$ & 375 & 375 \\
Amplitude of vibration $(\mathrm{mm})$ & 0.5 & 0.5 \\
\hline
\end{tabular}

yarn and the traveller. The value of $\mathrm{U} \%$, thick, thin and hairiness remain almost the same. The value of Neps increased a few percentages; it might be occurred for the low amount of surface scrapping.

Table V. Compare the properties of $\mathbf{1 0}$ and $20 \mathrm{Ne}$ cotton spun yarn

\begin{tabular}{llcccccccc}
\hline $\begin{array}{c}\text { Sample and } \\
\text { Experimental condition }\end{array}$ & $\begin{array}{c}\text { B. Strength } \\
(\mathrm{cN})\end{array}$ & Elon\% & $\mathrm{U} \%$ & $\begin{array}{c}\text { Thick } \\
50 \%\end{array}$ & $\begin{array}{c}\text { Thin } \\
50 \%\end{array}$ & $\begin{array}{c}\text { Neps } \\
200 \%\end{array}$ & Hairiness & $\begin{array}{c}\text { Hairiness } \\
\text { Co-efficient }\end{array}$ \\
\hline $10 \mathrm{Ne}$ & Without Vibration & 783 & 7.26 & 10.14 & 28 & 0 & 843 & 3.68 & 1.24 \\
& With Vibration & 828 & 7.28 & 10.24 & 43 & 0 & 1003 & 3.66 & 1.28 \\
$20 \mathrm{Ne}$ & Without Vibration & 249 & 5.82 & 12.14 & 168 & 5 & 1690 & 3.92 & 1.18 \\
& With Vibration & 270 & 7.94 & 12.39 & 157 & 13 & 1705 & 3.9 & 1.17 \\
\hline
\end{tabular}




\section{Conclusion}

The application and generation of vibration at the ring and the traveller indeed affects the frictional force of ring-traveller or co-efficient of friction between the ring and the traveller. Co-efficient of friction between the ring and the traveller decreases due to vibration. It is found that the percentage variation of yarn tension as well as friction co-efficient does not maintain any fixed co-relation with spindle speed.

\section{References}

Arnov VD', Souza AF, Kalpakjian S and Shareef I (1984a), Interactions among friction, wear, and system stiffness- Part I : Effect of normal load and system stiffness", ASME Journal of Tribology, 106: 54-58.

Arnov VD', Souza AF, Kalpakjian S and Shareef I (1984b), Interactions among friction, wear, and system stiffnessPart 2 : Vibration induced by dry friction, $A S M E$ Journal of Tribology, 106: 59-64.

Archard JF (1980), Wear theory and mechanism, in Peterson, M.B. and Winer, W.O.(Eds), Wear Control Handbook, ASME, New York, NY, pp. 35-80.

Barr, De and Catling, H, The Principles and Theory of Ring Spinning, Manual of Cotton Spinning, Volume 5 (1965), The Textile Institute, Butterworths Press, London.

Begum HA (2012), Ph. D Thesis, Effects of Vibration on the Twisting Rate of Ring Spinning for the Production of Yarn, Bangladesh University of Engineering and Technology.

Bushan B (1999), Principle and Applications of Tribology, John Wiley \& Sons, Inc., New York, pp. 344-430, Chap. 6.

Bushan B and Gupta BK (1991), Handbook of Tribology Materials, Coatings, and Surface Treatment, Mc-GrawHill, New-work,NY9reprint with corrections, Krieger, Malabar, FL.
Chowdhury MA and Helali MM. September (2006), The Effect of Frequency of Vibration and Humidity on the Co-efficient of Friction, Tribology International, 39: 958-962.

Chowdhury MA and Helali MM (2007), The Effect of Frequency of Vibration and Humidity on Wear Rate, Wear, 262: 198-203.

Chowdhury MA and Helali MM (2008). The Effect of Amplitude of Vibration on the Co-efficient of Friction, Tribology International, 41: 307-314.

Godfrey D (1967), Vibration Reduces Metal to Metal Contact and Causes an Apparent Reduction in Friction, ASME Transactions, 10: 183-192.

Grosberg P and Iype C, Yarn Production (Theoretical Aspects), (1999)The Textile Institute International, Biddles, UK.

Klein W, A Practical Guide to Ring Spinning, Manual of Textile Technology, Volume 4, (1995) The Textile Institute, MFP Design and Print, Manchester, UK,

Lenkiewicz W (1969), The sliding friction process- effect of external vibrations,' Wear, 13: 99-108.

Lord PR, Yarn Production (Science Technology and economics) (2003) The Textile Institute, Woodhead Publishing Limited, Cambridge England.

Skare T and Stahl J (1992), Static and dynamic friction processes under the influence of external vibrations, Wear, 154: 177-92.

Received: 02 April 2012; Revised: 28 June 2012; Accepted: 23 August 2012 . 